University of Wollongong

Research Online

Faculty of Engineering and Information

Faculty of Engineering and Information

Sciences - Papers: Part A

Sciences

$1-1-2013$

Utilising confinement reinforcement for shear resistance in reinforced concrete structures

Kamal Jaafar

University of Wollongong, kamal@uow.edu.au

Follow this and additional works at: https://ro.uow.edu.au/eispapers

Part of the Engineering Commons, and the Science and Technology Studies Commons

Research Online is the open access institutional repository for the University of Wollongong. For further information contact the UOW Library: research-pubs@uow.edu.au 


\title{
Utilising confinement reinforcement for shear resistance in reinforced concrete structures
}

\begin{abstract}
Common transverse reinforcement of reinforced concrete members with circular cross-section consists of round ties or spirals. Its purpose in members that are not subjected to significant shear loading is to provide proper confinement for concrete, and eliminate buckling of the longitudinal reinforcement bars. If spirals are to be used as both shear enabler and confiner for reinforced concrete beams then, under combined action of moment and shear, spirals will be required to provide or contribute to proper shear resistance. Hence, a proper assessment for spiral shear contribution is required. The validity of concepts which underline current methods for shear design used in design codes will be investigated in this paper, especially for beams with the shear configuration, which violates basic code rules on forming a truss. A simplified sectional model based on sectional crack analysis and a corresponding approach in assessing the shear contribution of spiral shear reinforcement are presented. A method for evaluating the shear capacity of beams with spirals has also been proposed.
\end{abstract}

\section{Keywords}

utilising, confinement, concrete, reinforcement, structures, shear, resistance, reinforced

\section{Disciplines}

Engineering | Science and Technology Studies

\section{Publication Details}

Jaafar, K. (2013). Utilising confinement reinforcement for shear resistance in reinforced concrete structures. Magazine of Concrete Research, 65 (4), 220-233. 


\section{Utilising confinement reinforcement for shear resistance in reinforced concrete structures}

Kamal Jaafar

University of Wollongong in Dubai, Dubai, United Arab Emirates

Common transverse reinforcement of reinforced concrete members with circular cross-section consists of round ties or spirals. Its purpose in members that are not subjected to significant shear loading is to provide proper confinement for concrete, and eliminate buckling of the longitudinal reinforcement bars. If spirals are to be used as both shear enabler and confiner for reinforced concrete beams then, under combined action of moment and shear, spirals will be required to provide or contribute to proper shear resistance. Hence, a proper assessment for spiral shear contribution is required. The validity of concepts which underline current methods for shear design used in design codes will be investigated in this paper, especially for beams with the shear configuration, which violates basic code rules on forming a truss. A simplified sectional model based on sectional crack analysis and a corresponding approach in assessing the shear contribution of spiral shear reinforcement are presented. A method for evaluating the shear capacity of beams with spirals has also been proposed.

\section{Notation}

$d_{\mathrm{sp}}$

effective core diameter between circular spirals

bar centre $=2 r_{\mathrm{sp}}$

$s_{\mathrm{sp}} \quad$ centre to centre spiral spacing

$V_{\mathrm{c}} \quad$ shear carried by concrete at the ultimate load

$V_{\mathrm{sp}} \quad$ shear force carried by the spirals

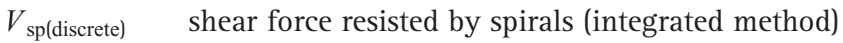

$V_{\text {sp(integration) }}$ shear force resisted by spirals (discrete method)

\section{Introduction}

The use of spiral links for preventing diagonal failures in beams will enable designers to utilise transverse reinforcement geometry for a better confinement effect. However, to develop such a model it is essential that better understanding of the actual structural behaviour of beams with different transverse shear reinforcement configuration is reached. This can be achieved by looking further into the concepts of shear transfer mechanisms and by investigating the influence of the spiral geometry on the level of shear contribution. In this paper, shear test results for beams reinforced with spiral links will be compared to the predictions of the following

- BS and Eurocode predictions

modified compression field theory through the programme 'Response' written by Ivan Benz and Michael Collins

- two-dimensional (2D) finite-element analysis

- integrated method for predicting the spiral shear contribution (this also covers the Caltrans and New Zealand Code)
- discrete method based on crack sectional analysis with an optimisation for the crack location with respect to the first link it crosses.

The discrete method based on sectional crack analysis is the analytical framework that is proposed in this paper. This method will help in evaluating the shear contribution of transverse reinforcement that violates truss mechanism.

\section{Spiral links and their application field}

The use of spiral links as transverse reinforcement is relatively uncommon in reinforced concrete beams. The idea of using spiral links as transverse reinforcement is commonly associated to columns with circular cross-sections. Hence, most of the literature available is for circular columns with circular hoops that are used as confinement. The circular shape of the spiral reinforcement is inherently efficient in providing confinement to the concrete core and resists longitudinal bar buckling. For this reason codes concentrate on confinement ratio for the spirals rather than their spacing and shear contribution.

Anderson and Ramirez (1989) experimented on stirrup detailing, finding that stirrups are required to mobilise yield under high shear stresses anywhere along their height due to the inclined nature of shear cracking. Clarke and Birjandi (1993) tried to assess the shear contribution of the spirals by considering them as a special case of inclined links where one leg on one side of the unit crosses a potential shear crack, while the leg on the other 
side runs generally parallel to the potential crack. Ziara et al. (1993, 1999) and Kotsovos and Pavlovic (1999) presented results from tests on simple beams that were reinforced in compliance with the compressive force path concept, using stirrups that did not extend the full depth of the beam. The test specimens when compared with the conventionally reinforced ones showed higher strength and ductility. According to Tsitotas and Tegos (1996) rectangular columns with two interlocking spirals were first proposed (and preferred to the conventional ones) by the competent US authority, the California Department of Transportation in 1983. Tsitotas and Tegos (1996) carried out one of the few tests on rectangular reinforced concrete beams with interlocking spirals. In the experiments the shear capacity was enhanced by the presence of the spiral links and shear failure was eliminated. Tsitotas recommended that further analytical and experimental investigation is required of the shear behaviour of members with spiral links.

\section{Experimental study}

The experimental program is divided into two stages. The first stage consists of static shear tests of simply supported beams at span to depth ratios $2 \cdot 27$ and 2.94. The second stage, cyclic testing, is applied to beams which have similar configuration to the ones tested in stage one. The test program was designed to examine the effectiveness of spirals as shear reinforcement. The beams were identical except for the transverse reinforcement provided. Two types of shear reinforcement were used: spirals fabricated from plain mild round steel wire, and normal closed rectangular stirrups.

To prevent any confusion, a brief summary of the terminology used to describe the various configurations of shear reinforcement examined now follows. The term 'spiral' refers to the helical shear reinforcement. As the spiral is laid at different parts of the beam, different terminology is used to indicate the position of the spirals within the beams.

- DS stands for double layers of spiral, one located entirely in the tension zone and the other located in the compression zone. They have no point of intersection between them except for the very thin wire that ties their ends together.

- IS stands for two interlocking spirals. The interlocking region $L_{\mathrm{i}}$ is equal to the radius of the spirals. To keep the interlocking region constant a thin wire was used to tie the two spirals together at their mid depth.

- NL stands for normal rectangular shear links made up from 4-mm plain steel bars.

- SSC stands for one single layer of spirals located entirely in the compression zone.

- SST stands for one single layer of spirals located entirely in the tension zone.

- PL stands for beam without shear reinforcement (plain beam).

The terms used to refer to the different tested beams are as follows
- first the stage number

- second the series number

- third the beam name and number.

For example

Stage I stands for the stage number 1

Series A stands for the series A

S A1 stands for the name of the beam

stands for the type of the test conducted (static in this case) ( $\mathrm{C}$ for cyclic tests)

Only stage one experimental results will be presented in this paper; more details can be found in Jaafar (2008)

\section{Experimental aims}

Experiments in stage one were done to test the behaviour of spirals when subjected to static shear and to quantify the amount of shear contribution in different geometrical configurations. It was also aimed to investigate the validity of using a simplified sectional crack analysis in assessing the shear behaviour in the conducted experiments. This is particularly relevant for beams reinforced with double and single spirals where tie action cannot easily form a simple truss system.

\section{Code predictions}

Eurocode and BS codes do not provide any guidelines for the shear design of specimens that have similar shear configuration to the beams tested in series B and C (Figure 1 and Table 1) (case of SB1, SB5, SC1, SC2, SC3 and SC4). Simply, it can be argued that such lack of guidance is a result of the new shear configuration used, which violates basic code rules on forming a truss. It can also be argued that because a tie action cannot form between the upper and the lower chord, code predictions in this case are equal to their predictions for the shear strength of normal concrete beams without any shear reinforcement. Hence, for beams with double spirals or even with spirals either in the compression or tensile zone, code prediction for the shear contribution of transverse steel is nil.

From the experimental information presented in Jaafar (2008), it becomes apparent that beams in stage I (case of SB1, SB5, SC1, $\mathrm{SC} 2, \mathrm{SC} 3$ and SC4) were capable of carrying higher shear loads, despite the fact that spirals did not connect the tension and compression chord of the beams. It would appear, therefore, that it is not a necessary condition for beams with such shear reinforcement configuration to behave (at ultimate limit state) as a truss in order to resist the action of shear forces as the absence of such reinforcement within the tensile or compression zone precludes the transformation of the beams into truss (or, at least, into a full-depth truss).

It is realistic, owing to the experimental results, to postulate that the mechanism of the contribution of transverse reinforcement to shear capacity is similar to that of the longitudinal reinforcement 

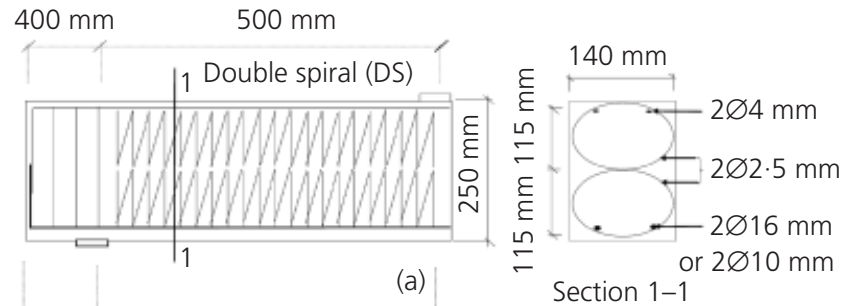

Interlocking spirals (IS)

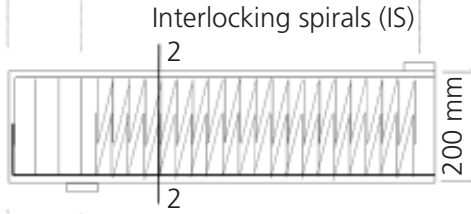

(b)

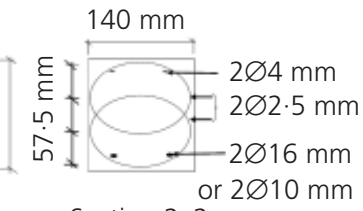

Section 2-2

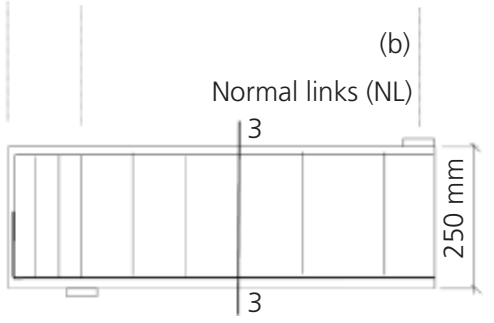

(c)

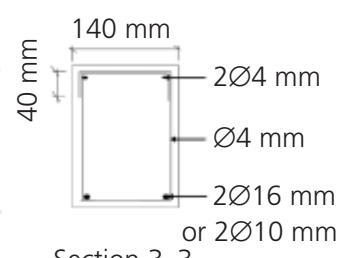

Section 3-3

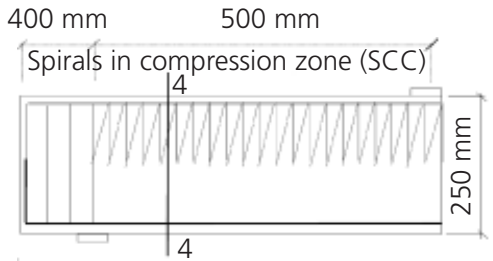

(d)

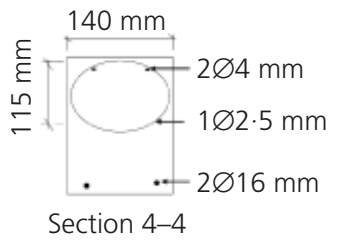

Spirals in tension zone (SST)

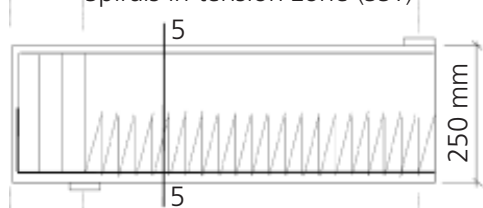

(e)
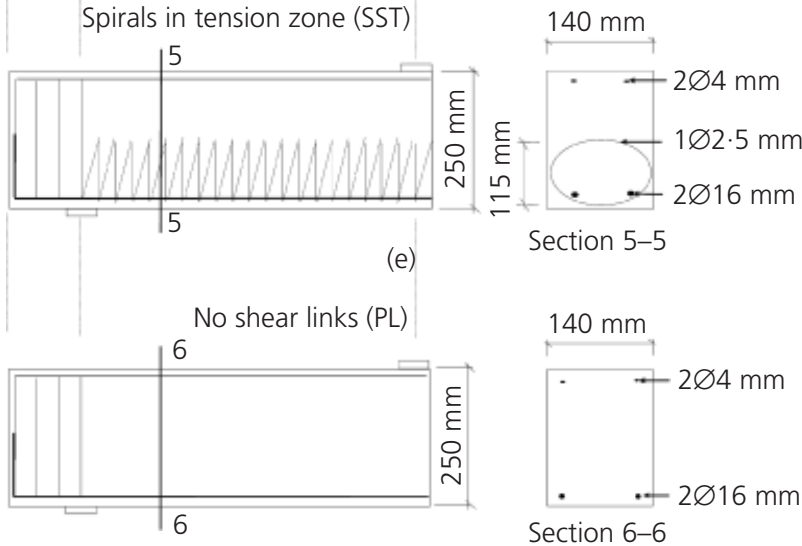

(f)

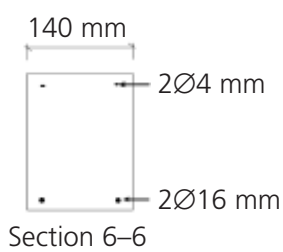

Section 6-6

Figure 1. Details of specimen reinforcement: (a) SBI

$\left(s_{\mathrm{sp}}=65 \mathrm{~mm}\right)$ and SB5 ( $\left.s_{\mathrm{sp}}=32 \mathrm{~mm}\right) ;($ b) SB3; (c) SB2; (d) SC 1

$\left(s_{\mathrm{sp}}=65 \mathrm{~mm}\right)$ and C3 $\left(s_{\mathrm{sp}}=32 \mathrm{~mm}\right) ;\left(\right.$ e) SC2 $\left(s_{\mathrm{sp}}=65 \mathrm{~mm}\right)$ and

SC4 $\left(s_{\mathrm{sp}}=32 \mathrm{~mm}\right)$; (f) SD1 (case of $h=250 \mathrm{~mm}$ ) and SD2 (case

of $h=200 \mathrm{~mm}$ )

to flexural capacity, in that the reinforcement is capable of sustaining the portion of the tensile action that cannot be sustained by the concrete on its own.

\section{Analysis using modified compression field theory}

To analyse the beams with spiral shear reinforcement presented in Jaafar (2008) and briefly described in Figure 1 and Table 1, and to test if the modified compression field theory is a suitable method for predicting the attained results, a computer package (Response) developed by Ivan Bentz and MP Collins at the University of Toronto is used. Their program is based on the modified compression field theory. The program uses sectional analysis to calculate the strength and ductility of a reinforced concrete cross-section subjected to shear, moment and axial load. All three loads are considered simultaneously to find the full load-deformation behaviour. 'Response' allows for simulating columns with circular hoops, yet it does not model confinement (although this can be simulated with the segmental concrete model that can be used as an input option). According to Bentz (2000), hoop strains are accounted for and they are calculated from the transverse strain based on Mohr's circle.

In 1995 both Nigel Priestley and Gianmario Benzoni from University of California (Budek et al., 1995) conducted a series of tests on columns with spiral shear reinforcement. The results of one of these tests, Inter-4, was used by MP Collins to show the effectiveness of his program and the modified compression field theory in predicting and simulating the results of specimens reinforced with interlocking circular hoops. To illustrate the effectiveness of the program 'Response' in simulating concrete members with similar shear configuration to the one tested in Jaafar (2008) (series B and C, stage I), the predicted results conducted by Collins for Inter-4 are shown in Figure 2, where the accuracy of the program is quite apparent.

For the analysis of series B and C beams, properties of steel and concrete used in the analysis were obtained from experimental data, except for the tensile strength of concrete, where slightly higher values were used for calibration purposes. Figures 3 to 6 show a comparison between the 'Response' analysis and the experimental results. 'Response' failed to give a good prediction both in terms of predicting the failure crack pattern and the ultimate shear loads for beams that could not support a full-depth truss. The failure loads predicted by the program for SB5 (spirals not intersecting), SC3 and SC4 were close to the predictions it gave for beams without any shear reinforcement, type SD1 (see Figure 5 and Figure 6). For the beam with double spirals, SB5, the problem of low shear prediction was overcome by forcing the two spirals to intersect in the analysis (note: this was not the case in 


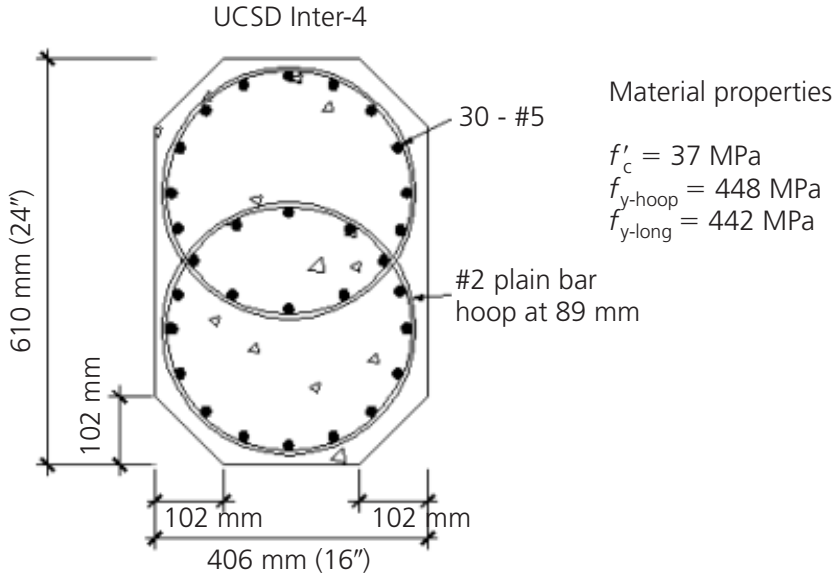

Clear cover to outside of hoop $14 \mathrm{~mm}$ all sides

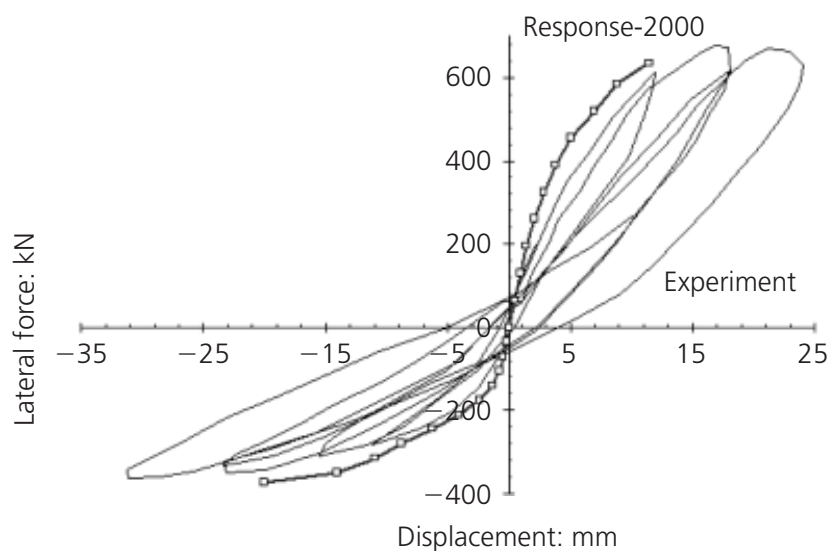

Figure 2. Response analysis performed by Evan Bentz and Michael Collins for Enter-4, on experiments done by Priestley and Benzoni

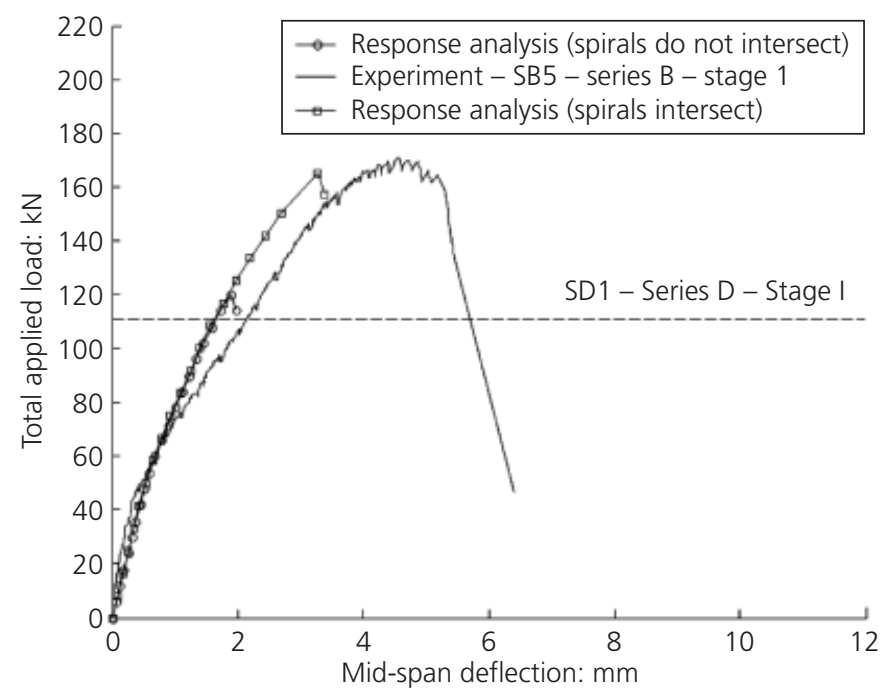

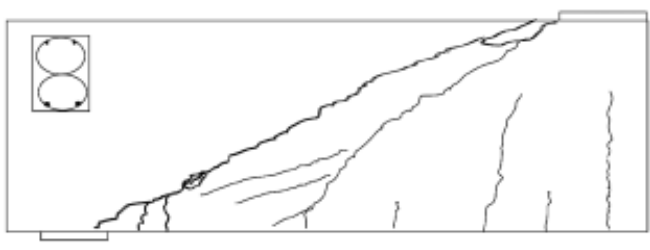

Experimental crack pattern for SB5 series B - stage I

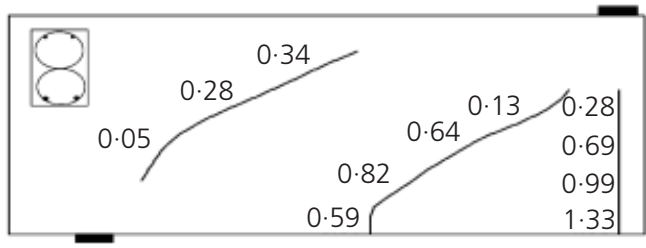

Response crack pattern for SB5 - series B stage I (spirals assumed to intersect)

Figure 3. Comparison between experimental results and

response analysis for beam SB5 - series B - stage I

the experiment). By ensuring continuity between the upper chord and the lower chord of the beam through interlocking spirals a good prediction was obtained (see Figure 3 and Figure 4).

The low predictions that the program showed for the case of SC3, SC4 and SB5 are also reflected in the variation of the spiral stresses shown in Figure 7. Spiral stresses in cases where connectivity is ensured between the two layers of spirals (either through analysing interlocking spirals SB3 or through forcing two spirals to intersect for the case of double spirals SB5) are much higher than those where spiral continuity is not present. By forcing the two spirals to connect in the program, beams were capable of resisting higher shear loads as a result of spiral contribution. For interlocking spirals, spiral stresses reached to yielding values indicating the dependability of the program on the connectivity of the spirals to provide good predictions. Such behaviour is expected as the program is based on the modified compression field theory, which is an extension of the truss analogy theory. According to personal discussion with Evan Bentz the following is quoted: 'Response will indeed give poor results if two sets of spirals are not interlocking as it will assume a vertical crack can form between the two reinforced sections and act poorly'.

In conclusion, the program acts as a very handy tool for assessing the behaviour of beams/columns with a single spiral (i.e. one 

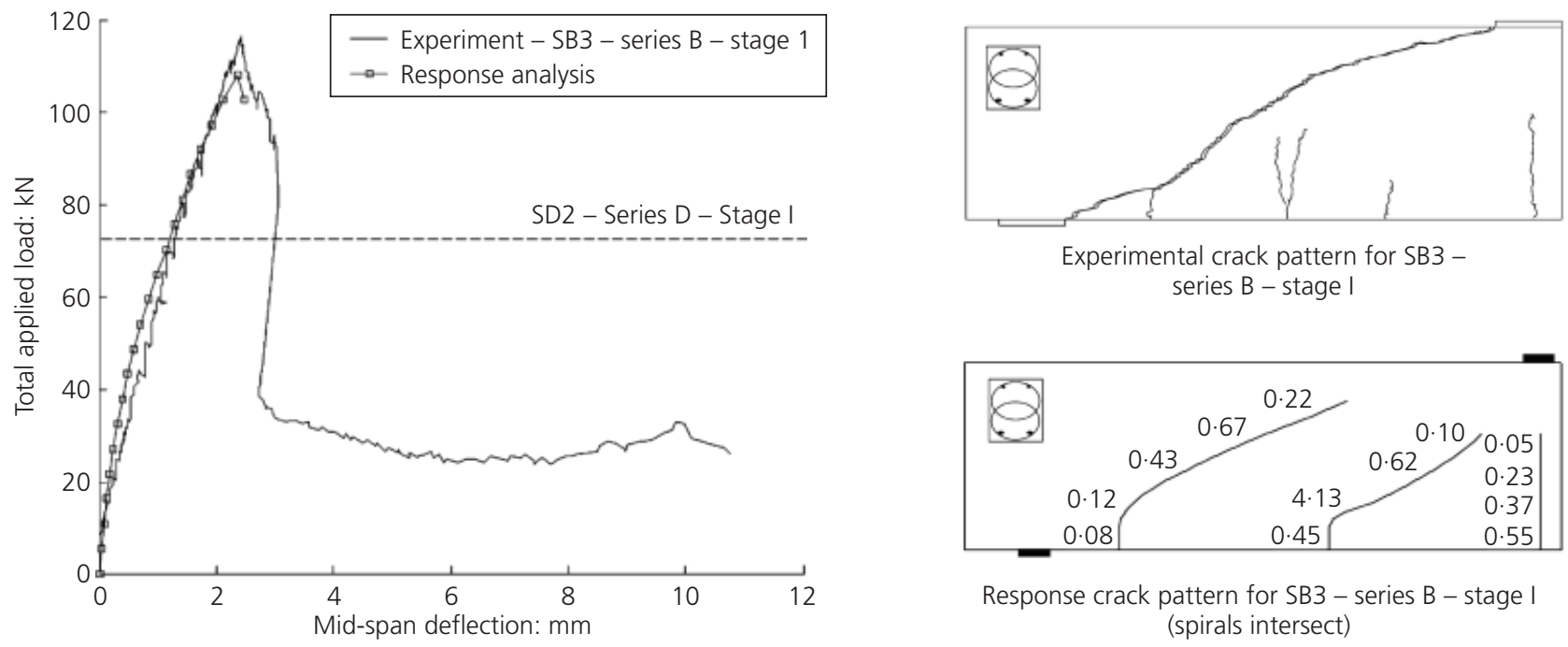

Response crack pattern for SB3 - series B - stage I (spirals intersect)

Figure 4. Comparison between experiment results and response analysis for beam SB3 - series B - stage I
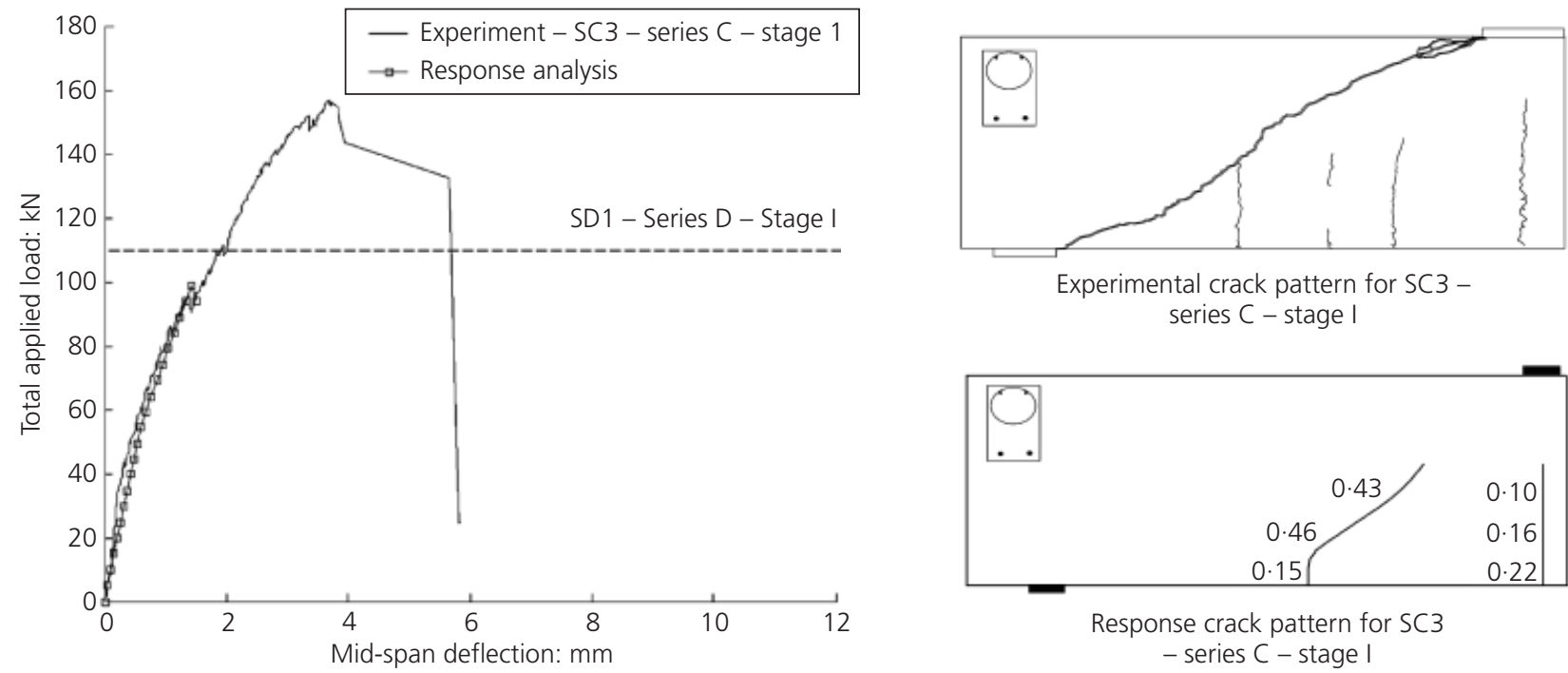

Experimental crack pattern for SC3 series $C$ - stage I

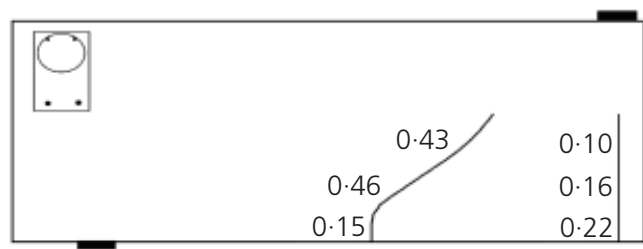

Response crack pattern for SC3 - series C - stage I

Figure 5. Comparison between experimental results and response analysis for beam SC3 - series $\mathrm{C}$ - stage I

layer of spirals joining the upper chord to the lower one) or interlocking spirals. Yet it failed to simulate the results of beams that had spirals either in the compression or tension zone, even though it showed a slight increase in the spiral stresses.

\section{Non-linear finite-element analysis}

Modelling of reinforced concrete using non-linear finite-element analysis is not straightforward because of the complexities involved in the behaviour of concrete (Kotsovos, 1986; Lowes et al., 2004; Lykidis and Spiliopoulos, 2008; Park and Klinger, 1997). Some of the complexities of the problem are outlined as follows.
- The structural system is three-dimensional (3D) and is composed of two different materials, concrete and steel.

- The structural system has a continuously changing character owing to the cracking of concrete under increasing load.

- Effects of dowel action in the steel reinforcement, bond between the steel reinforcement and concrete, and the bond slip are difficult to incorporate into a general analytical model.

- The stress-strain relationship for concrete is non-linear and is a function of many variables.

- Concrete deformations are influenced by creep and shrinkage and are time-dependent. 


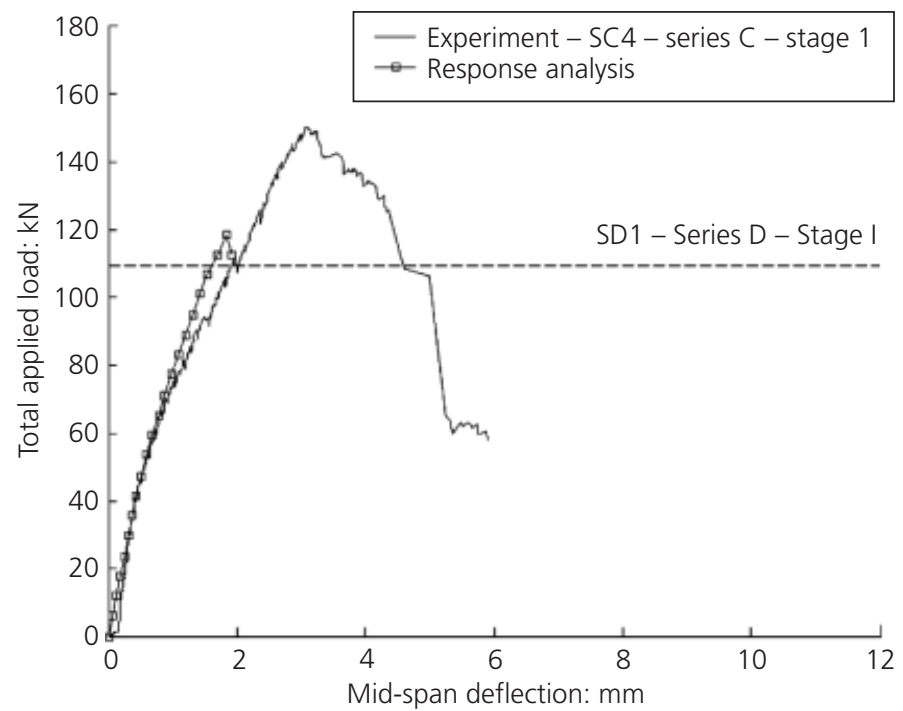

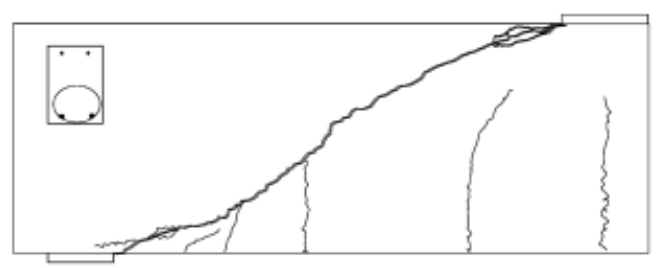

Experimental crack pattern for SC 4 - series C stage I

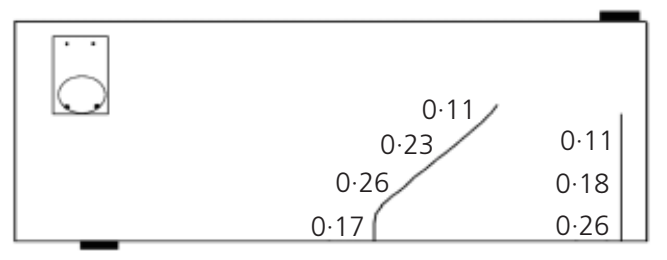

Response crack pattern for SC3 - series C - stage I

Figure 6. Comparison between experimental results and response analysis for beam SC4 - series $C$ - stage I
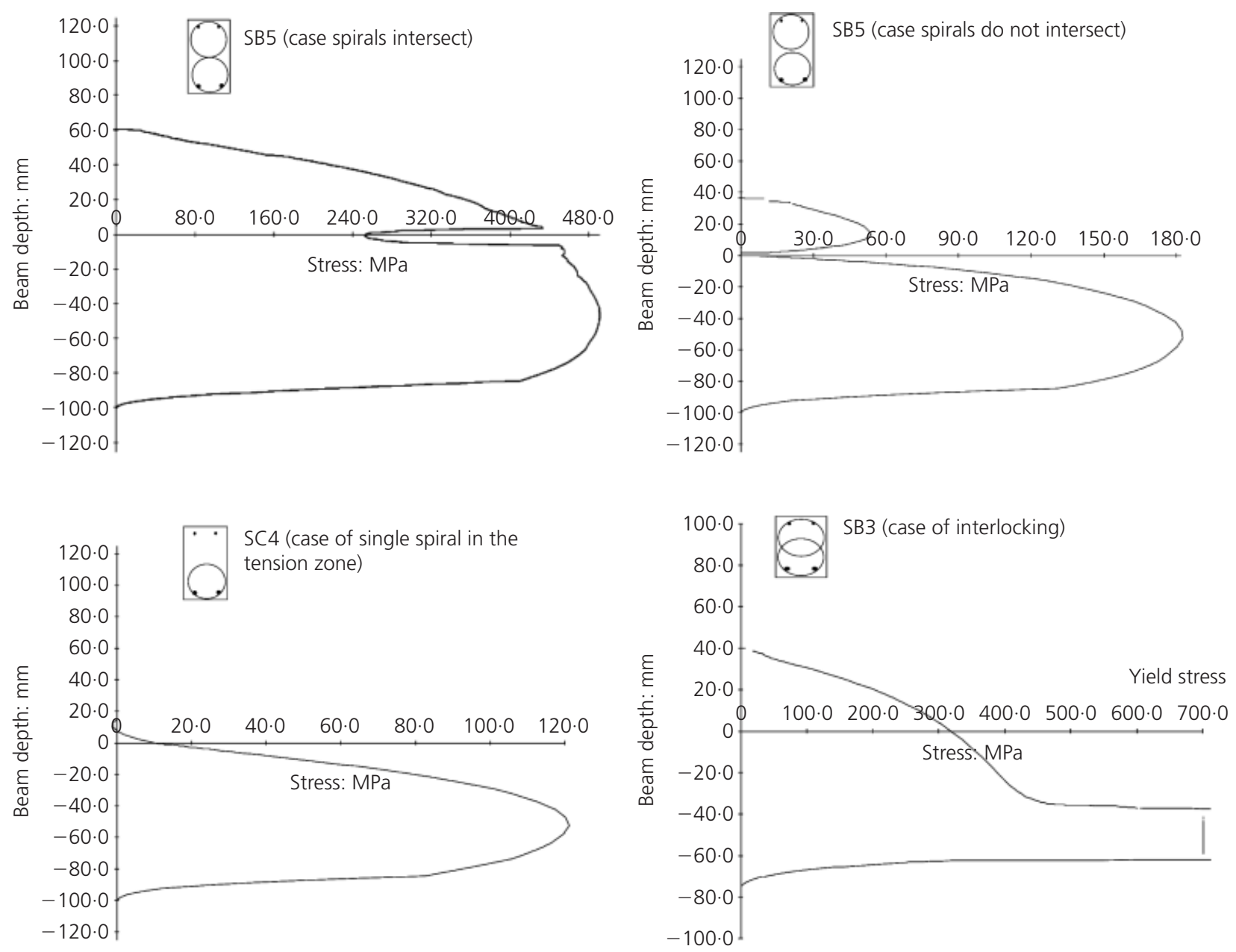

Figure 7. Spiral stress variation for different configurations using Response 
It is not the purpose of this study to present finite element formulations and modelling, which have been extensively covered elsewhere. The aim of the analytical simulation using finiteelement (FE) was to determine the ability, or inability, of the FE model to identify particular features of the beam behaviour and the mode of failure, especially for those reinforced with spiral links.

An attempt to model beams with spiral links in 3D form was made using Abaqus, a commercial FE package; yet, because of the complexity encountered in the meshing criteria of the circular spirals, a 2D analysis was adopted instead. In the analysis, the spirals' circular geometry was simplified to a linear one similar to that of standard links. Even though this is a significant simplification, the phenomena of having a double or single spiral in a beam can still be investigated through analysing its shear failure mechanism. For this purpose, beams SB3, SB5, SC3 and SC4 were analysed and compared with the experimental results.

\section{Mesh modelling}

For the analysed beams, the element size was chosen to be three times the aggregate size. Four-noded elements were used to model the concrete, while two-noded bar elements were used to model both the reinforcing and the spiral link bars. The vertical 2-node elements representing the spiral links were placed as closely as possible to their experimental positions. A perfect bond was assumed between concrete and reinforcing bars. Appropriate displacement boundary conditions at nodes over roller support were imposed.

\section{Material modelling}

The non-linear elastic isotropic model is implemented in this study because it shows a good correlation with experimental data and it only needs one parameter to define the whole behaviour of concrete. The isotropic strain model is used to describe the deformational behaviour of concrete and to incorporate the coupling between normal strains and deviatoric stresses. This model is path independent and intended for monotonic loading, which means that the stress-strain curve during unloading will follow the same path as that during loading. The model is capable of stimulating the ascending portion of the stress-strain curve of concrete under short-term static loading conditions up to the strength envelope.

\section{Failure loads}

The failure of all beams, predicted from the present analysis, occurs owing to shear failure. Agreement between experiments and predictions from the present analysis of the ultimate load is thought to be quite reasonable in terms of both the shear failure mode and the contribution of the shear links to the shear failure load.

\section{Load-deflection relationship}

A comparison between the total load against mid-span deflection curve obtained from the present analysis and experiments for the four selected beams (series B and C -stage I) is shown in Figure 8 for SB3 and SB5, and in Figure 9 for SC3 and SC4. The experimental results have been included for comparison purposes. The initial stiffness predicted by the present FE analysis agrees well with that observed in the experiments, but, after diagonal cracks started to occur, the analysed beams showed higher stiffness than the experimental values.

\section{Crack patterns}

The crack patterns do not show individual cracks because of the 'smeared' crack approach. Abaqus, the FE program used in the analysis, does not allow its user to plot the crack pattern if the implicit version is used for the analysis. Yet, from the output data files it was possible to check the elements that have cracked. The FE analysis was able to capture the crack path and the extensive cracking that appeared at the last load stage. At the final stage the load dropped as a limit point was passed. Vertical cracks initiate over the mid-span and failure occurs because of
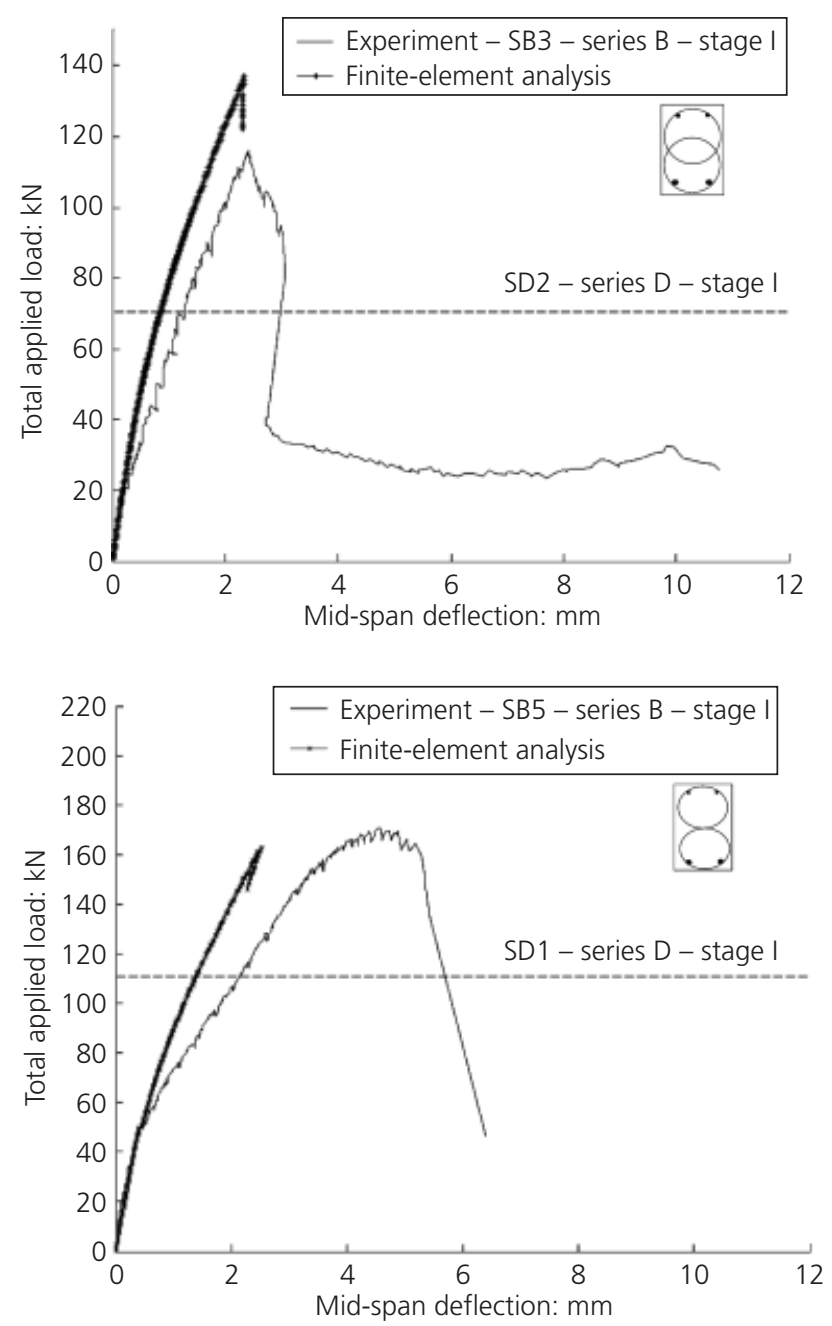

Figure 8. Comparison between experimental results and FE analysis for beam SB3 and SB5 - series B - stage I 

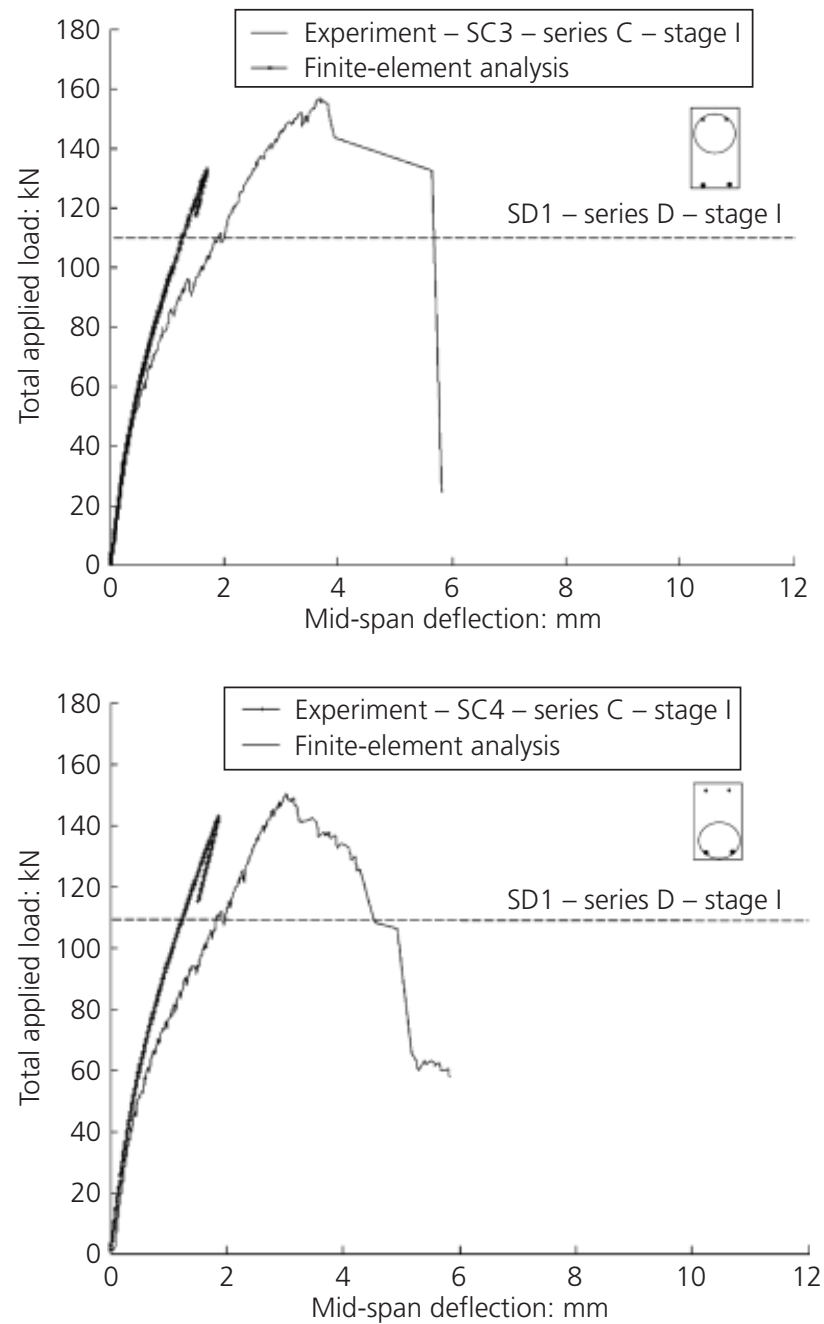

Figure 9. Comparison between experimental results and FE analysis for beam SC3 and SC4 - series C - stage I

excessive crack in the shear span, as, indeed, happened in the test. The shear link elements remained nearly unstressed until shear cracks occurred.

\section{Discussion}

The results attained by the 2D FE analysis were very significant for explaining the possibility of shear enhancement for the case of spirals that were located in the tension or compression zone. Some simplifying assumptions have been made in this study as a result of the complexity involved in modelling the exact geometrical configuration of the tested beams. Simplifying the geometry of the spirals by representing them with bar elements is a major generalisation which can contradict the argument presented in Jaafar (2009) regarding the importance of considering the geometrical properties of the spirals in assessing their shear contribution. Yet, as mentioned earlier, 3D analysis was attempted but, owing to the complexity involved, a 2D analysis was adopted instead. The positive finding from the $2 \mathrm{D}$ analysis presented in this section is attributed to the fact that shear enhancement is possible even if the bar elements representing spiral links do not join the tension chord to the compression chord. Hence, the bar elements contributed to the shear loads by enhancing cracked concrete elements. Analysis of the four beams showed a considerable contribution of the spirals to the ultimate shear capacity. The contribution is a result of the enhancement of the bar elements to the concrete elements once smeared cracks take place in the latter.

Another simplification that is worth discussing is the perfect bond assumed between concrete and bar elements for the shear links. This assumption can be validated and explained in terms of the good anchorage system of the spiral links owing to their continuous circular shape.

\section{Optimised discrete method and average integration method predictions spiral shear contribution}

In assessing the shear contribution of spirals, most codes overestimate the spiral shear performance by assuming that their shear resistance is the same as that of normal links. Ghee et al. (1989) investigated this phenomenon and proposed an analytical expression based on an average integration method for reinforced concrete elements with circular cross-section. Tanaka and Park (1993) and Benzoni et al. (2000) used the average integration method for designing the shear capacity of the columns they have tested. The New Zealand Code (NZS, 1995) and the Caltrans (Caltrans, 2001) adopt the same method, and the $\pi / 4$ factor was introduced.

Jaafar (2009) studied the shear carried by transverse circular reinforcement in reinforced concrete elements. The paper examined the average integrated model that codes adopt to calculate the shear contribution of single spiral. Jaafar proposed a discrete model which is based on imaginary crack sectional analysis for calculating the shear contribution of spiral links. His comparison between the integrated and the discrete method showed that for a relatively large pitch of the spirals and for a variable crack inclination angle, the integral computation that most codes adopt yields results that are $10 \%$ to more than $50 \%$ non-conservative (Figure 10).

Based on crack-sectional analysis where a discrete method is considered and a variable crack inclination angle is assumed, the prediction for spiral shear contribution using the optimised discrete method that Jaafar (2009) proposed was a reasonable and safe prediction (Table 2). It is important to note that there is no control over the exact location of the inclined failure surface. As it is hard to predict the definite inclination angle for an experimental shear crack, a range was assumed. Therefore, in calculating the shear resistance, $V_{\mathrm{sp}}$, an optimisation technique was considered where the crack location and inclination angle were varied before selecting the optimal value. In optimising $V_{\mathrm{sp}}$ 
Utilising confinement reinforcement for shear resistance in reinforced concrete structures

Jaafar

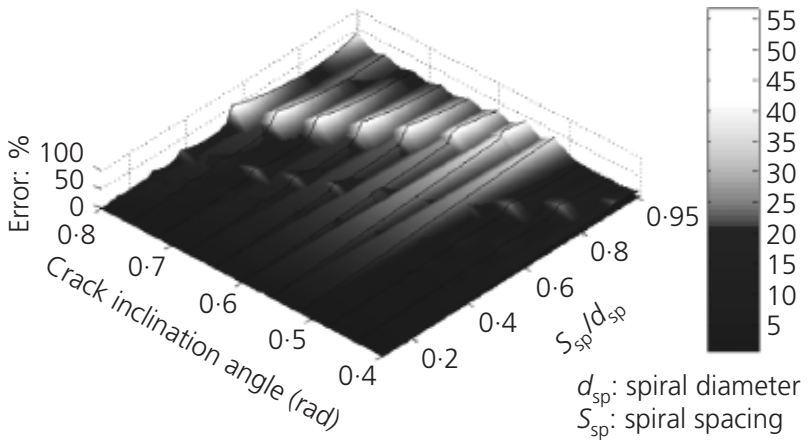

(a)

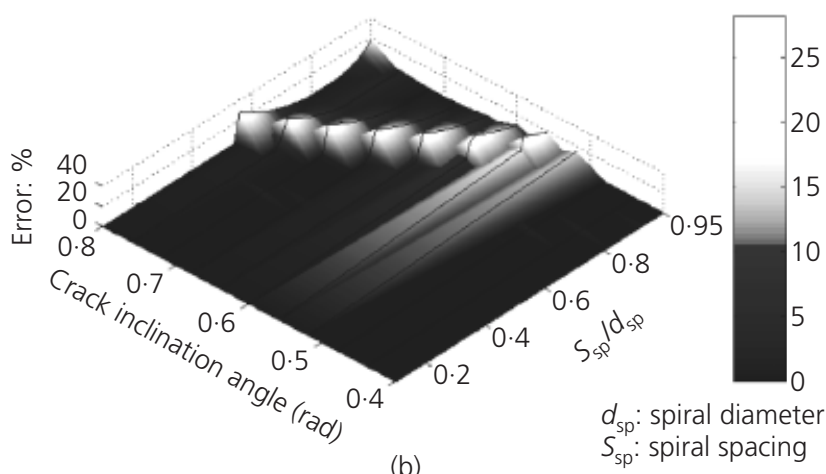

(b) both the location of the spiral and the angle was varied for constant spiral spacing and a minimum value was calculated.

The average integration predictions that codes recommend for the shear contribution of the spirals for some of the beams were outside the range that might be assumed for a possible experimental crack inclination angle (see Table 2). Even at a crack inclination angle of $45^{\circ}$, an angle usually used in shear design, the integration method predicted values higher than the one calculated for the experimental spiral shear contribution. The reason for these out-of-range predictions can be attributed to the overestimation of the behaviour of the average integration method for the spiral shear contribution as a result of the assumption made which neglected the effect of spiral geometry on the shear force variation.

It is important to stress that the values reported in Table 2 (values for $V_{\mathrm{sp}}$ ) for the experimental spiral shear contribution are based on assumptions made by many researchers and codes that the shear strength is a summation of the contributions of the concrete and the shear reinforcement. To calculate the normalised concrete shear contribution, the following procedures were followed.

- Code rules were used to calculate the concrete shear contribution $V_{\mathrm{c}}$ (see Table 2).

- All factor of safety assumed by codes are removed in calculating $V_{\mathrm{c}}$ ( or $\left.V_{\mathrm{rd} 1}\right)$.

- Beam SD1 and SD2 were considered to be reference beams,

Figure 10. Error variation induced by integral averaging formulation as a function of crack inclination angle and transverse reinforcement spacing for the case of double and interlocking spirals respectively (Jaafar, 2009)

\begin{tabular}{|c|c|c|c|c|c|c|c|c|c|c|}
\hline \multirow[t]{3}{*}{ ID } & & \multirow[t]{3}{*}{$V_{\text {exp }}: k N$} & \multirow[t]{3}{*}{$V_{c}: k N$} & \multirow[t]{3}{*}{$V_{\mathrm{sp}}: \mathrm{kN}$} & \multicolumn{3}{|c|}{$\begin{array}{c}V_{\mathrm{sp}} \text { discrete: } \mathrm{kN} \\
\text { Based on optimum (min.) values }\end{array}$} & \multicolumn{3}{|c|}{$V_{\text {sp }}$ (average integration): kN } \\
\hline & & & & & $\alpha=45^{\circ}$ & $\alpha=35^{\circ}$ & $\alpha=30^{\circ}$ & $\alpha=45^{\circ}$ & $\alpha=35^{\circ}$ & $\alpha=30^{\circ}$ \\
\hline & & & & & Design & \multicolumn{2}{|c|}{$\begin{array}{c}\text { Possible crack inclination } \\
\text { angle }\end{array}$} & Design & \multicolumn{2}{|c|}{$\begin{array}{c}\text { Possible crack inclination } \\
\text { angle }\end{array}$} \\
\hline SD1 & $\mathrm{PL}$ & $55 \cdot 7$ & $55 \cdot 7$ & - & - & - & - & - & - & - \\
\hline SD2 & $\mathrm{PL}$ & 35.6 & 35.6 & - & - & - & - & - & - & - \\
\hline SB1 & DS & $69 \cdot 7$ & 53.62 & $16 \cdot 08$ & $11 \cdot 12$ & $19 \cdot 1$ & 24.48 & $18 \cdot 56$ & $26 \cdot 48$ & $32 \cdot 16$ \\
\hline SB2 & $\mathrm{NL}$ & $83 \cdot 28$ & 52.93 & $30 \cdot 35$ & - & - & - & - & - & - \\
\hline SB3 & IS & 58.09 & $34 \cdot 31$ & $23 \cdot 78$ & $13 \cdot 32$ & 24.65 & $30 \cdot 81$ & $15 \cdot 98$ & $22 \cdot 61$ & $27 \cdot 47$ \\
\hline SB4 & $\mathrm{NL}$ & $54 \cdot 2$ & $34 \cdot 31$ & $19 \cdot 89$ & - & - & - & - & - & - \\
\hline SB5 & DS & $85 \cdot 3$ & $54 \cdot 75$ & $30 \cdot 55$ & $23 \cdot 78$ & $45 \cdot 96$ & $56 \cdot 92$ & $37 \cdot 12$ & $53 \cdot 01$ & $64 \cdot 29$ \\
\hline SC1 & SSC & $72 \cdot 9$ & $56 \cdot 69$ & $16 \cdot 21$ & $5 \cdot 56$ & $9 \cdot 58$ & $12 \cdot 24$ & $9 \cdot 28$ & $13 \cdot 24$ & $16 \cdot 08$ \\
\hline SC2 & SST & $67 \cdot 4$ & $56 \cdot 08$ & $11 \cdot 32$ & $5 \cdot 56$ & $9 \cdot 58$ & $12 \cdot 24$ & $9 \cdot 28$ & $13 \cdot 24$ & $16 \cdot 08$ \\
\hline SC3 & SSC & 78.25 & $55 \cdot 48$ & $22 \cdot 77$ & 11.89 & 22.97 & 28.46 & $18 \cdot 56$ & $26 \cdot 48$ & $32 \cdot 17$ \\
\hline SC4 & SST & 75 & 55.95 & $19 \cdot 05$ & $11 \cdot 89$ & 22.97 & 28.46 & $18 \cdot 56$ & $26 \cdot 48$ & $32 \cdot 17$ \\
\hline
\end{tabular}

$V_{c}$ concrete shear contribution

$V_{\text {sp }}$ is the spiral shear contribution $=V_{\exp }-V_{c}$

Table 2. Spiral shear contribution based on discrete and average integration method 
and their experimental shear contribution $V_{\mathrm{c}(\mathrm{ref})}$ was used for normalising purposes.

- Once $V_{\mathrm{c}}\left(\right.$ or $\left.V_{\mathrm{rd} 1}\right)$ is calculated it is then normalised with respect to a reference beam that have the same dimensions.

The reference beams in the current study are those without any shear reinforcement (SD1 and SD2). When calculating the spiral shear contribution using the average integration method, the formula reported in Jaafar (2009) was used at different crack inclination angles

at $45^{\circ}$ (a typical design angle for shear)

at $30^{\circ}-35^{\circ}$ (a possible experimental crack inclination angle).

The discrete method was also used to calculate the spiral shear for the same angles mentioned above, yet the values reported in Table 2 are the minimum values obtained from varying the position of the crack location with respect to the spiral links. Figures 11 to 13 show the variation of the spiral shear contribution as both the crack inclination angle and its location with respect to the link it crosses vary. For each crack inclination angle, the points shown in the figures are those obtained as the minimum and maximum shear force obtainable by varying the location of the crack longitudinally relative to the links. The process by which the optimised variation was plotted is described in the flow chart shown in Figure 14. The $x$-axis represents inclination angle, while the $y$-axis represents the predicted spiral shear force. It is noticeable that the variation is not linear because of the spirals geometry. The optimised discrete method showed results that are quite reasonable in the region of the assumed experimental crack inclination angle (see Table 2). The straight line plotted in the graphs showing the experimental spiral shear contribution is based on the assumption taken previously in this section where the concrete shear contribution is for simplicity assumed constant and calculated from Eurocode equations. Concrete shear contribution varies probably with crack inclination angle, but as the main interest is to assess the shear contribution of spirals and their shear transfer mechanism, it was decided to simplify the concrete shear contribution by calculating a normalised value based on Eurocode 8 (CEN, 1996) and European Committee for Standardisation (CEN, 1992).

According to Figure 11 and Figure 12 the spirals shear force variation calculated using the optimised discrete method for large spiral spacing, the case of SB1, SC1 and SC2, seems to be more sensitive to crack position and its inclination angle. However, the shear force sensitivity becomes lower for small spiral spacing (case of SB5, SC3 and SC4). The reason for such behaviour has been discussed in Jaafar (2009) where it was shown that shear force sensitivity is a function of spiral geometry, spacing and crack inclination angle.

It appears from the data presented that the numerous deviations of the predictions of current design methods from the experimental behaviour are attributable to the inadequacy of the theor-
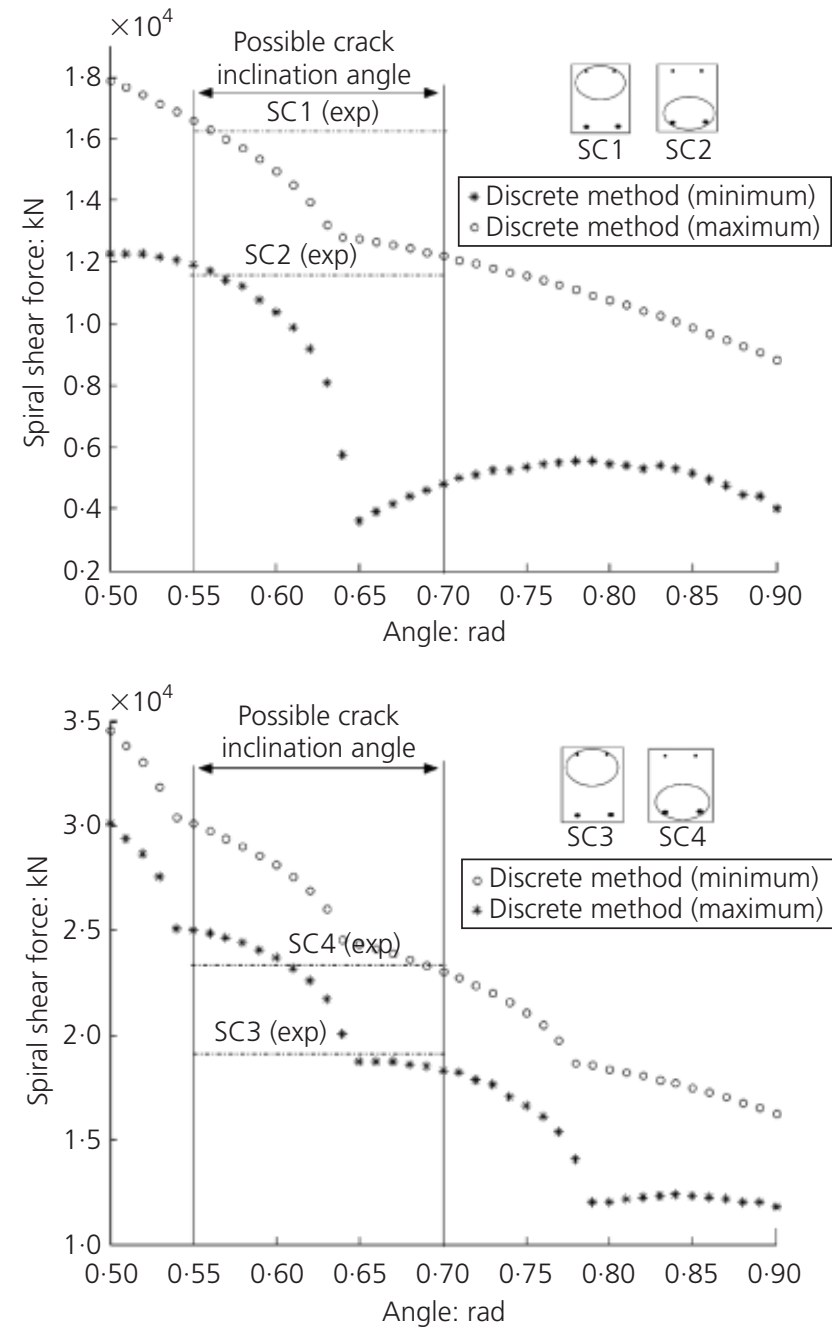

Figure 11. Maximum and minimum spiral shear force obtained for SC1, SC2, SC3 and SC4 using discrete method

etical basis of the methods currently used for assessing the shear capacity of such members. The code predictions were very low in comparison to other methods (Figure 15). Codes do not cover such types of shear reinforcement arrangement for reinforced concrete beams. The Caltrans and New Zealand codes specify rules for the case of reinforced concrete columns confined with spiral links. Those two specific codes adopt the average integration method in assessing the shear contribution of single spiral and, in the case of interlocking spirals, they emphasise the importance of providing longitudinal bars to assure shear force transition from one spiral to the other. The provision of longitudinal bars in case of interlocking spirals (column case) is an essential code rule as columns are subjected to high compression stresses, which might lead into spiral separation. This is not the case for beams, as the experiments showed no spiral separation in all the conducted experiments.

The predictions obtained by the Response program failed to give 

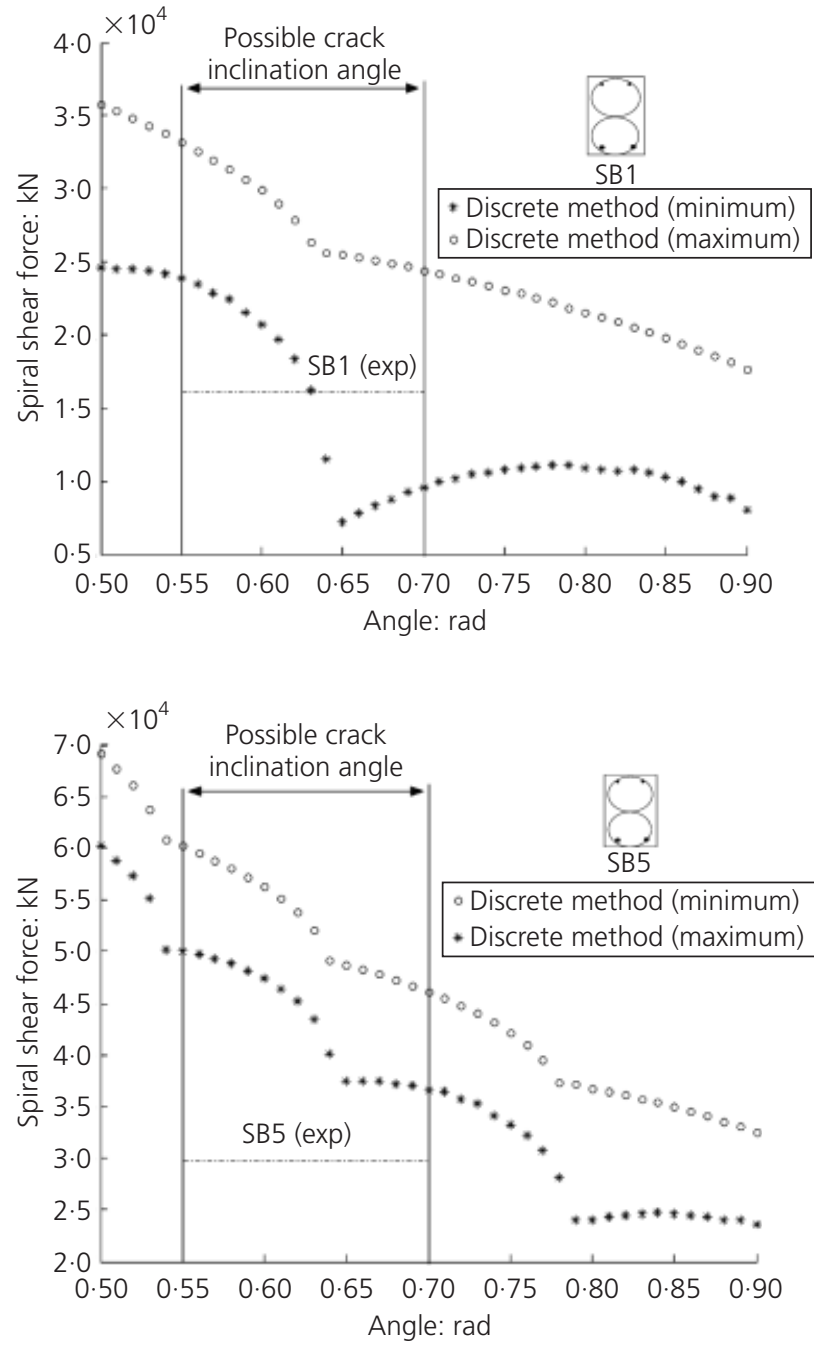

Figure 12. Maximum and minimum spiral shear force obtained for SB1 and SB5 using discrete method

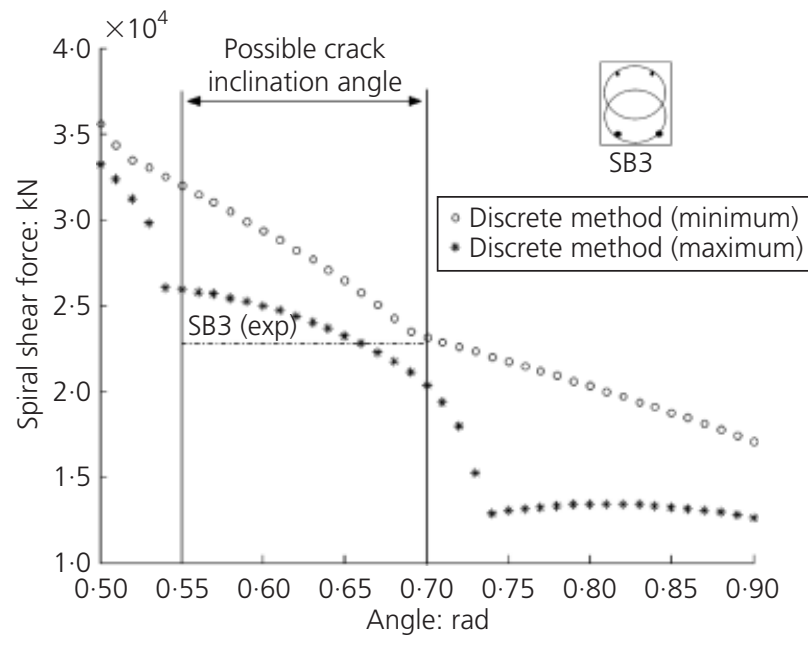

Figure 13. Maximum and minimum spiral shear force variation obtained for SB3 using discrete method a full explanation for the results attained in Jaafar (2008). It succeeded in simulating both the failure mode and the ultimate load for the beam with interlocking spirals. It acts as a very handy tool for the assessment of members with complex shear configurations (i.e. beams with interlocking spirals) as it takes into consideration both equilibrium and compatibility, together with spiral circular geometry. Yet, similar to the codes, it failed to simulate the results of beams with shear reinforcement configurations that do not permit the usual simple truss to form.

The 2D FE analysis was a very useful tool to explain the shear enhancement that resulted from the presence of spirals in different sectors of the beam. The FE model was able to capture the overall behaviour of the beams with spiral links even though significant simplifications were adopted. The mode of failure was well detected and the links with different configuration contributed to the ultimate shear load as predicted by the analysis. The analysis gave further indication of how beams with SSC, SST and DS shear configuration were able to carry the applied shear loads. Many improvements can be introduced for a better modelling, yet those improvements are quite expensive in terms of the complexity involved.

Based on sectional analysis that takes into consideration the vertical equilibrium of the forces contributing to the shear carrying mechanism, it was demonstrated that the optimised discrete method was a proper tool for predicting the shear contribution of spirals and, hence, it is a suitable design tool for assessing the spiral shear contribution, provided that the factors influencing its prediction are taken into consideration.

\section{Conclusion}

In view of the results, it is therefore not surprising that in his recent, award-winning article 'Myth and fallacies in earthquake engineering' Priestley (1997) devoted a section to what he rightly described as 'the shear myth(s)' Significantly, he stated: 'Shear design of reinforced concrete is so full of myths, fallacies, and contradictions that it is hard to know where to begin in an examination of current design. Perhaps the basic myth central to our inconsistencies in shear design is that of shear itself'. On the basis of the above findings, the following conclusions are made.

- The average integration method for assessing the spiral shear contribution is inadequate, especially in the case of steep crack inclination angle and large spiral spacing. A discreet approach is a more reliable tool for assessing the spiral shear contribution.

- From the experimental evidence presented in Jaafar (2008), it was apparent that many concepts underlying current design methods were incompatible with observed experimental results (especially in the case where a full depth truss could not form inside beams of type SSC and SST).

- Crack sectional analysis proved to be an adequate tool for designing beams with unconventional shear reinforcement 

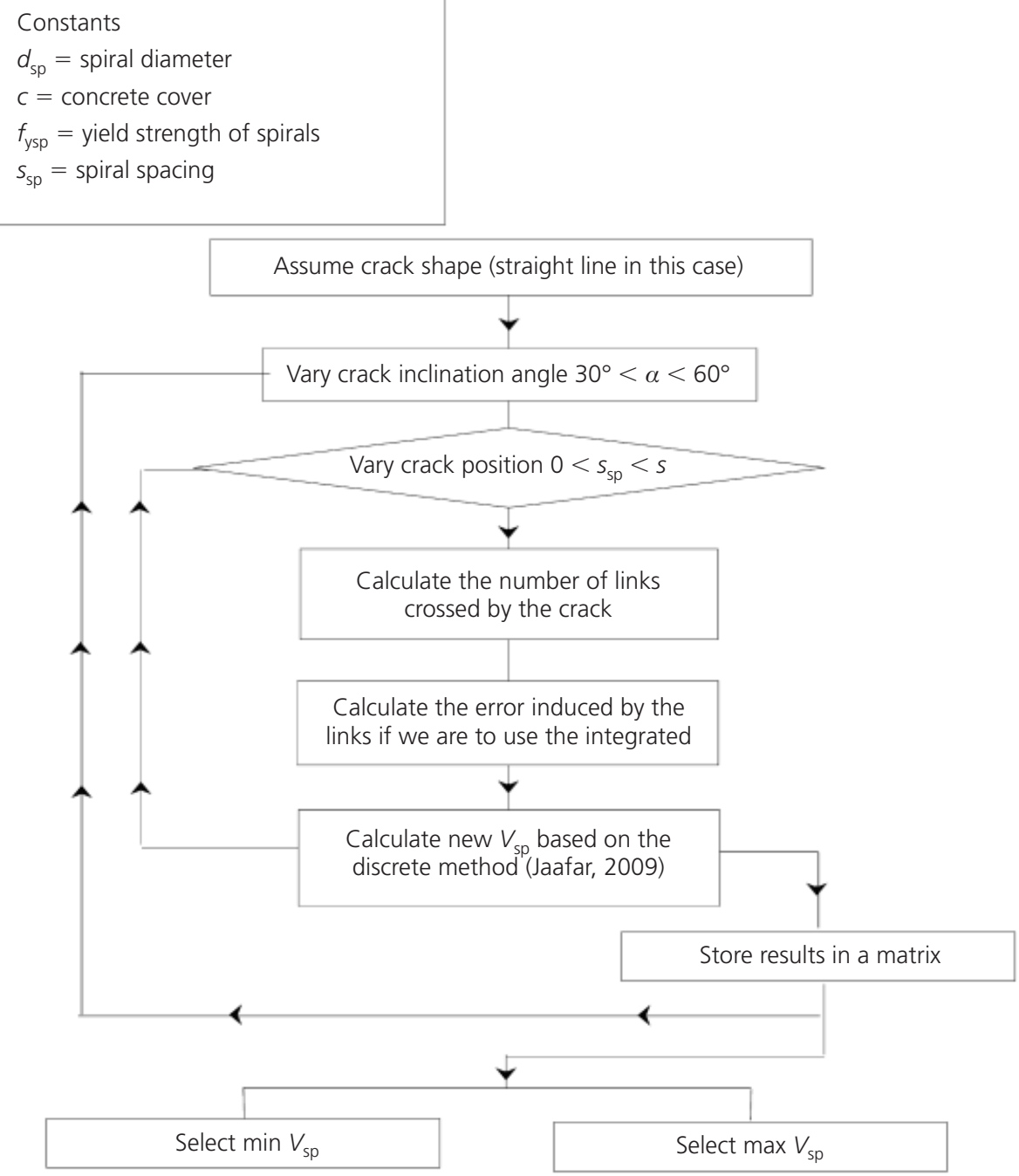

Figure 14. Flow chart for optimising $V_{\text {sp }}$
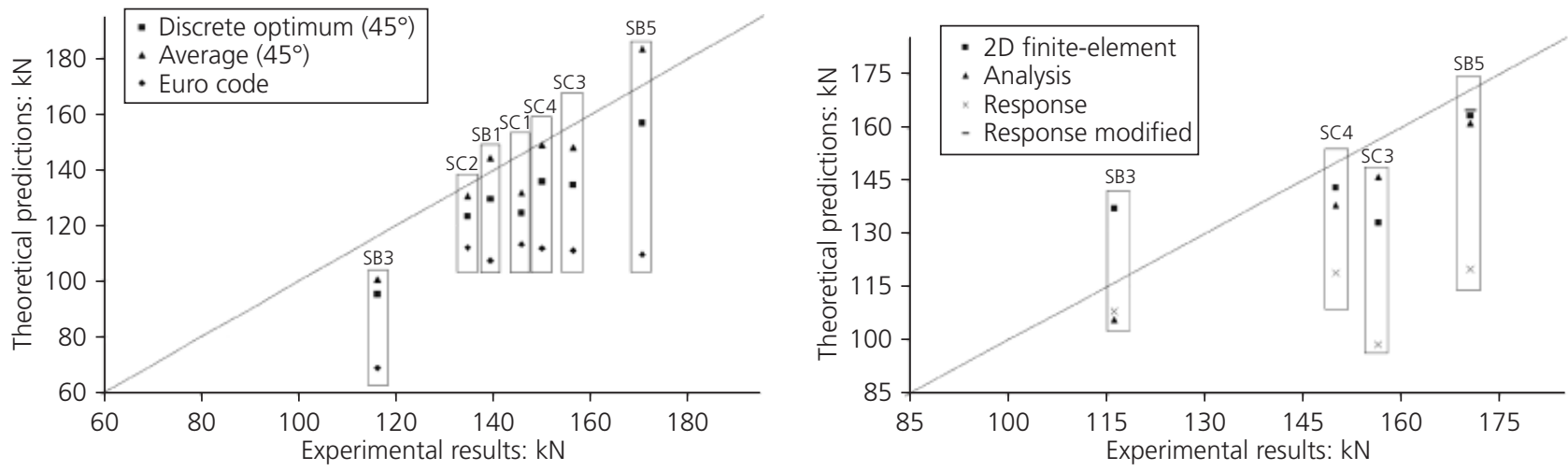

Figure 15. Correlation for beams tested in series II - stage I with various methods for designing 
provided that the discrete method is also used to calculate the spirals' shear contribution.

\section{Acknowledgement}

The author wishes to express his gratitude and sincere appreciation to Dr CT Morley from the University of Cambridge for his support, fruitful discussion and scientific guidance.

\section{REFERENCES}

Anderson NS and Ramirez JA (1989) Detailing of stirrup reinforcement. ACI Structural Journal 86(5): 507-515.

Bentz EC (2000) Sectional Analysis of Reinforced Concrete Members. PhD thesis, University of Toronto, USA.

Benzoni G, Priestley MJN and Seible F (2000) Seismic shear strength of columns with interlocking spiral reinforcement. In Proceedings of 12th World Conference on Earthquake Engineering, Auckland, New Zealand. Paper no. 1562.

Budek A, Benzoni G and Priestley MJN (1995) Analytical Study of the Inelastic Seismic Response of Reinforced Concrete Pile-Columns in Cohesionless soil. La Jolla, California, USA.

Caltrans (California Department of Transportation Division of Engineering Services) (2001) Seismic Design Criteria. Caltrans, California, USA.

Clarke JL and Birjandi FK (1993) The behaviour of reinforced concrete circular sections in shear. The Structural Engineer 71(5/2): 73-79.

CEN (European Committee for Standardization) (1996) Eurocode 8. Design provisions for earthquake resistance of structures. Part1.1-1.3. BSI, London, UK.

CEN (1992) Eurocode 2: Design of Concrete Structures, Part 1. General rules and rules for buildings. BSI, London, UK.

Ghee AB, Priestley MJN and Paulay T (1989) Seismic shear strength of circular reinforced concrete columns. ACI Structural Journal 86(1): 47-59.

Jaafar K (2008) Shear behaviour of reinforced concrete beams with confinement near plastic hinges. Magazine of Concrete Research 60(9): 665-672.

Jaafar K (2009) Discrete versus average integration in shear assessment of spiral links. Canadian Journal of Civil Engineering 36(2): 171-179.

Kotsovos MD (1986) Non linear finite element modelling of concrete structures: basic analysis, phenomenological insight and design implications. Engineering with Computers 3(3): 243-250.

Kotsovos MD and Pavlovic MN (1999) Ultimate Limit-State Design of Concrete Structures. Thomas Telford, London, UK.

Lowes LN, Moehle JPS and Govindjee S (2004) Concrete-steel bond model for use in finite element modeling of reinforced concrete structures. ACI Structural Journal 101(4): 501-511.

Lykidis KV and Spiliopoulos KV (2008) 3D solid finite-element analysis of cyclically loaded RC structures allowing embedded reinforcement slippage. Journal of Structural Engineering, ASCE 134(4): 629-638.

NZS (Standards Association of New Zealand) (1995) NZS3101. Code of practice for design of concrete structures. NZS, Wellington.

Park H and Klinger RE (1997) Nonlinear analysis of RC members using plasticity with multiple failure criteria, Journal of Structural Engineering 123(5): 643-651.

Priestley MJN (1997) Myths and fallacies in earthquake engineering. Concrete International 19(2): 54-63.

Tanaka H and Park R (1993) Seismic design and behaviour of reinforced concrete columns with interlocking spirals. $A C I$ Structural Journal 90(2): 192-203.

Tsitotas MA and Tegos IA (1996) Seismic behaviour of $r / c$ columns and beams with interlocking spirals. In Earthquake Resistant Engineering Structures (Brebbia CA, Manolis GD and Beskos DE (eds)). WIT Press, Southampton, UK, pp. 449-461.

Ziara MM, Haldane D and Kuttab AS (1993) Shear and flexural strengths resulting from confinement of the compression regions in circular section structural concrete. Magazine of Concrete Research 45(164): 211-219.

Ziara MM, Haldane D and Kuttab AS (1999) Preventing of diagonal tension failures in beams using flexure-shear interaction approach. Magazine of Concrete Research 51(4): $275-289$.

\section{WHAT DO YOU THINK?}

To discuss this paper, please submit up to 500 words to the editor at www.editorialmanager.com/macr by 1 August 2013. Your contribution will be forwarded to the author(s) for a reply and, if considered appropriate by the editorial panel, will be published as a discussion in a future issue of the journal. 